\title{
Acompanhamento laboratorial da função renal de cães sadios tratados experimentalmente com doses terapêuticas de anfotericina $B$
}

\author{
Laboratorial accompaniment of kidney funtion of health dogs experimentally treated with therapeutic \\ dosages of amphotericin $B$
}

Flávia Santin ${ }^{1}$ Flávio Quaresma Moutinho² AnneSantos doAmaral ${ }^{3}$ Regina Kiome Takahira $^{2}$

\section{RESUMO}

O presente trabalho objetivou avaliar a função renal de dez cães adultos saudáveis submetidos à administração de doses terapêticas do antifúngico anfotericina $B$, cuja utilização tem sido limitada pelo seu elevado potencial nefrotóxico, e avaliar o método laboratorial mais sensível e precoce de diagnóstico de lesão renal. Foram realizadas, diariamente, urinálise, excreção fracionada de sódio e potássio, dosagem sérica de creatinina e uréia e atividade urinária de $\gamma$ glutamiltransferase (GGT). Concluiu-se que a anfotericina $B$ provoca lesões nos túbulos proximal e distal, induzindo acidose tubular renal do tipo I e Diabetes insipidus nefrogênico em cães. Avaliação da função renal, preferencialmente por dosagens de creatinina, uréia e potássio séricos, é recomendada antes de cada aplicação do fármaco. A densidade urinária foi o parâmetro mais precocemente alterado pela lesão renal. A GGT urinária não foi eficaz para o diagnóstico precoce de lesão induzida por anfotericina $B$.

Palavras-chave: anfotericina $B$, função renal, $\gamma$ glutamiltransferase urinária, excreção fracionada, cães.

\section{ABSTRACT}

The objective of this experiment was to assess the renal function of ten healthy male adult dogs submitted to therapeutic doses of amphotericin B, whose use has been limited due to its high nephrotoxic potential, as well as to evaluate the more sensitive and early method to diagnose kidney lesions. The renal function was evaluated through daily urinalysis, fractioned excretion of sodium and potassium, serum concentration of creatinine and blood urea nitrogen (BUN) and urinary activity of gamma-glutamyltransferase (GGT). It was concluded that amphotericin $b$ provokes lesions in both proximal and distal tubules, inducing type I renal tubular acidosis and nephrogenic Diabetes insipidus in dogs. Renal function evaluation, preferably by serum creatinine, BUN and potassium dosage is recommended before each drug application. Urinalysis proved to diagnose kidney lesions in its earliest stage through a modification of the density parameters. Urinary GGT was not effective as an earliest diagnose kidney lesions caused by amphotericin $B$.

Key words: amphotericin $B$, kidney function, urinary $\gamma$ glutamyltransferase, fractioned excretion, dogs.

\section{INTRODUÇÃO}

A anfotericina B é um antibiótico macrolídeo poliênico, com potente ação antifúngica, também utilizado no tratamento da leishmaniose, cuja aplicação tem sido limitada pelo seu elevado potencial nefrotóxico (MONTEIRO et al., 1993). Seu regime terapêutico veterinário foi desenvolvido empiricamente pela combinação de limites de toxicidade, experiência clínica, dados de uso em humanos e conveniência. A dose utilizada é de $0,5 \mathrm{mgkg}^{-1}$, reconstituída em água para injeção e diluída em glicose a 5\%, administrada em dias alternados por via intravenosa (SCOTT et al., 2001).

$\mathrm{A}$ anfotericina $\mathrm{b}$ liga-se às membranas celulares criando um canal iônico transmembrana que permite o fluxo de íons e pequenas moléculas intracelulares (HARVEY \& CHAMPE, 1998). Com a saída desses íons, principalmente do potássio, há o comprometimento do metabolismo celular, podendo ainda ocorrer rompimento da membrana e morte celular (SCOTT et al., 2001). A modificação da permeabilidade

${ }^{1}$ Faculdade de Medicina Veterinária e Zootecnia (FMVZ), Universidade Estadual Paulista (UNESP), Botucatu, SP, Brasil. E-mail: fla_vet@ig.com.br. Autor para correspondência.

${ }^{2}$ Departamento de Clínica Veterinária, FMVZ, UNESP, Botucatu, SP, Brasil.

${ }^{3}$ Autônoma. 
iônica pode alterar o co-transporte de glicose para o interior das células, hipótese sugerida por JOLY et al. (1989), que demonstraram a alteração da permeabilidade ao sódio das membranas das bordas em escova dos túbulos proximais renais em ratos e coelhos tratados com anfotericina B.

Este fármaco provoca intensa constrição vascular renal, levando à diminuição do fluxo sangüíneo (BAGATIN \& CUCÉ, 1983) e à conseqüente diminuição do ritmo de filtração glomerular (SABRA et al., 1990). Este efeito vasoconstritor da arteríola aferente ocorre por ação direta do fármaco sobre os vasos renais, provocando a entrada intracelular de cálcio, induzindo sua despolarização e contração vascular (GRAUER \& LANE, 1997).

A anfotericina B causa insuficiência renal não-oligúrica, provavelmente dose-dependente, dias a semanas após o início do uso do fármaco; em seres humanos, são relatadas diminuição da capacidade de concentração urinária, alterações degenerativas e regenerativas dos túbulos proximal e distal e obstrução luminal por detritos necróticos (BAGATIN \& CUCÉ, 1983). RUBIN (1988) afirmou não ter observado alterações que comprovassem a existência das lesões no túbulo proximal. SAWAYA et al. (1995) descreveram a ocorrência de alteração na capacidade de acidificação urinária em seres humanos tratados com anfotericina B. CARLSON \& CONDON (1994) citaram a presença de proteinúria variável relacionada ao uso de anfotericina B. RANDALL et al. (1996) alertaram sobre a importância das variações individuais ao ser instituído um tratamento com a anfotericina $\mathrm{B}$.

A urinálise e a determinação das concentrações séricas de creatinina e uréia são métodos convencionais utilizados para a avaliação da função renal (STRASINGER, 2000). Cães normais têm capacidade, diretamente ligada à hipertonicidade medular e ao hormônio antidiurético, de concentrar urina acima de 1.025; qualquer distúrbio no qual ocorra falha estrutural ou funcional na capacidade de concentração urinária pode ser denominado diabetes insipidus nefrogênico (DIBARTOLA, 2000). A quantidade de qualquer substância na urina deve ser interpretada juntamente com a densidade: isto é particularmente válido para proteínas e glicose, pelo potencial significado clínico representado pela detecção destas substâncias em urinas diluídas (MEYER \& HAVEY, 1998). Urinas de cães normais apresentam pequenas quantidades de proteínas, geralmente entre traços a 1+, e nenhuma glicose. Virtualmente toda glicose é reabsorvida nos túbulos proximais por co-transporte de glicose com sódio, a não ser que a glicemia seja superior a $180 \mathrm{mgdl}^{-1}$
(DiBARTOLA, 2000). Na insuficiência renal aguda, ocorre glicosúria normoglicêmica devido à presença de significativas lesões tubulares (TILLEY \& SMITH, 2003). O pH urinário de cães varia entre 5 e 7,5; dentre as causas de pH alcalino estão a onda alcalina pósprandial, os agentes alcalinizantes e a acidose tubular distal renal (DıBARTOLA, 2000). Em cães normais, o sedimento urinário consiste apenas de pequenas quantidades de células. Cilindros granulosos formamse no interior dos túbulos renais em consequiência de lesão tubular (MEYER \& HARVEY, 1998). Por serem estruturas muito frágeis, os cilindros desintegram-se rapidamente, especialmente em urinas alcalinas ou muito diluídas (TILLEY \& SMITH, 2003).

A presença de eletrólitos na urina ocorre como resultado dos processos de reabsorção e secreção tubulares. A excreção fracionada dos eletrólitos pode ser utilizada na avaliação da função tubular, sendo definida como a relação entre o eletrólito em questão e a eliminação de creatinina (DıBARTOLA, 2000). Animais com função renal normal apresentam excreção fracionada de $\mathrm{Na}^{+}\left(\mathrm{EF}_{\mathrm{Na}}\right)$ inferior a $1 \%$ e de $\mathrm{K}^{+}\left(\mathrm{EF}_{\mathrm{K}}\right)$ inferior a 24\% (GRAUER \& LANE, 1997, DIBARTOLA, 2000). MONTEIRO et al. (1993) observaram que a excreção fracionada de sódio manteve-se inalterada logo após a infusão de anfotericina diretamente na artéria renal de cães. DÓREA et al. (1997) demonstraram ocorrência de EFNa reduzida e EFK aumentada em ratos tratados com anfotericina B.

A enzima $\gamma$-glutamiltransferase (GGT) está presente na borda em escova dos túbulos proximais renais e sua detecção na urina tem sido apontada como um bom método diagnóstico para lesão ou disfunção tubular renal (RIVERS et al., 1996). Atividade urinária entre 13 a $92 \mathrm{UL}^{-1}$ é observada em cães normais (DeSCHEPPER et al., 1989).

O presente trabalho objetivou avaliar a função renal de dez cães adultos saudáveis submetidos à administração de doses terapêuticas do antifúngico anfotericina B e avaliar o método laboratorial mais sensível e precoce para o diagnóstico de lesão renal.

\section{MATERIAL E MÉTODOS}

O presente estudo foi aprovado pela Câmara de Ética em Experimentação Animal da Faculdade de Medicina Veterinária e Zootecnia da Universidade Estadual Paulista (FMVZ-UNESP), campus Botucatu. Foram utilizados dez cães hígidos sem raça definida, machos, adultos, com peso entre 10 e $15 \mathrm{~kg}$, provenientes do canil do Biotério da UNESP-Botucatu. Estes animais foram submetidos à avaliação clínica e laboratorial e mantidos em jaulas individuais de 
alvenaria com tablado de madeira removível, acesso livre a solário, água ad libitum e ração comercial em duas porções diárias. Após um período de dez dias de ambientação, foram colhidas três amostras de sangue e urina de cada animal, em um mesmo dia, para a obtenção dos valores basais, sendo utilizada sua média aritmética como valor controle. A anfotericina $\mathrm{B}^{\mathrm{a}}$ foi administrada sempre às $12 \mathrm{~h}$, na dose terapêutica de $0,5 \mathrm{mgkg}^{-1}$, diluída em $20 \mathrm{~mL}$ de solução glicosada a 5\%, via intravenosa, na velocidade de $1,3 \mathrm{~mL} \mathrm{~min}^{-1}$, em dias alternados ( $1^{\circ}, 3^{\circ}, 5^{\circ}, 7^{\circ}$ e $9^{\circ}$ dias $)$.

Amostras de urina foram colhidas às $8 \mathrm{~h}$ (M1 a M10) e às 16h (T1 a T10), por meio de micção espontânea ou cateterismo vesical por sonda uretral, por dez dias consecutivos. A urinálise foi realizada na urina recém-colhida e centrifugada em tubo cônico a 500G por cinco minutos. Após a centrifugação da amostra, o sobrenadante foi separado do sedimento e utilizado para a realização dos exames físico e químico da urina com refratômetro portátil e fita reagente ${ }^{\mathrm{b}}$, respectivamente, e para a determinação da atividade de GGT com kit comercial ${ }^{c}$. O sedimento urinário foi examinado após sua ressuspensão em uma gota do sobrenadante, disposto entre lâmina e lamínula e observado em microscopia óptica com objetiva de 40 vezes. Alíquotas de $1 \mathrm{~mL}$ de sobrenadante da urina colhida às $16 \mathrm{~h}$ foram armazenadas em tubos tipo eppendorf, mantidas em freezer $\mathrm{a}-80^{\circ} \mathrm{C}$ para dosagem de creatinina ${ }^{\mathrm{d}}$, sódio ${ }^{\mathrm{e}}$ e potássio ${ }^{\mathrm{f}}$ urinários, a qual foi realizada no Laboratório de Emergência ${ }^{\mathrm{g}}$ do Hospital das Clínicas da Faculdade de Medicina da UNESP Botucatu (HC-FMB).

Os valores da atividade da GGT urinária foram corrigidos pela fórmula descrita por DeSCHEPPER et al. (1989), que utilizam a densidade urinária 1.025 como fator de correção para o fluxo urinário de uma única amostra, tal que $\mathrm{X}=\mathrm{Y} \cdot 25 / \mathrm{Z}$, onde $\mathrm{X}$ é a atividade da GGT urinária calculada; $Y$ é a atividade da GGT urinária da amostra e Z corresponde aos últimos dois dígitos da densidade urinária da amostra.

Para a obtenção dos valores da excreção fracionada dos eletrólitos, utilizou-se a fórmula: $\mathrm{EF}_{\mathrm{x}}=$ $\left(\mathrm{U}_{\mathrm{X}} \mathrm{P}_{\mathrm{CR}}\right)\left(\mathrm{U}_{\mathrm{CR}} \mathrm{P}_{\mathrm{X}}\right)$, onde: $\mathrm{EF}_{\mathrm{X}}=$ excreção fracionada do eletrólito a ser avaliado; $\mathrm{U}_{\mathrm{X}}=$ concentração do eletrólito na urina; $\mathrm{P}_{\mathrm{X}}=$ concentração plasmática do eletrólito; $\mathrm{U}_{\mathrm{CR}}=$ concentração da creatinina na urina; $\mathrm{P}_{\mathrm{CR}}=$ concentração plasmática da creatinina (DIBARTOLA, 2000).

Foram também realizadas colheitas de amostras de $10 \mathrm{~mL}$ de sangue todos os dias às $16 \mathrm{~h}(\mathrm{~T} 1$ a T10), por venopunção jugular com tubos a vácuo, centrifugadas após a coagulação na velocidade de 1600G, para separação do soro, utilizado na determinação de creatinina ${ }^{\mathrm{h}}$ e uréia ${ }^{\mathrm{i}}$. Para dosagem de $\mathrm{Na}^{+}$e $\mathrm{K}^{+}$, foi colhido um volume mínimo de $0,7 \mathrm{~mL}$ de sangue por venopunção com seringa de $1 \mathrm{~mL}$ umedecida com heparina ${ }^{\mathrm{j}}$, acondicionado imediatamente após a colheita em isopor com gelo e processado em um período de até 30 minutos no Laboratório de Emergência do HC-FMB.

As variáveis quantitativas foram analisadas por estatística descritiva. As variáveis creatinina e GGT urinária foram submetidas à transformação logarítmica para estabilizar a variância. Utilizou-se a análise de variância para medidas repetidas para avaliar as médias ao longo dos momentos estudados e, quando o teste mostrou significância estatística, utilizaram-se contrastes para discriminar as diferenças. Valores de $\mathrm{P}<0,05$ foram considerados estatisticamente significantes.

\section{RESULTADOS E DISCUSSÃO}

Embora não tenham sido utilizadas gaiolas metabólicas, houve visível aumento do volume urinário de todos os cães. A urina era predominantemente de cor amarelo-clara, odor sui generis e aspecto límpido. Não houve em momento algum a presença de corpos cetônicos, urobilinogênio ou sais biliares na urina dos animais do presente experimento. A bilirrubina mantevese dentro dos valores de $1+$ a $2+$. Pequenas quantidades de cristais (fosfato triplo, fosfato e urato amorfos) foram encontradas. Não foram observadas alterações na quantidade de células renais, de pelve ou uroteliais.

Todos os cães apresentaram densidades urinárias significativamente diminuídas já após quatro horas da primeira aplicação do fármaco (Tabela 1), com valores máximos observados durante o experimento sempre abaixo de 1.025 , valor considerado normal para cães com livre acesso à água (DiBARTOLA, 2000). A excreção fracionada de $\mathrm{Na}+(\mathrm{EFNa})$ foi sempre inferior a $1 \%$ (Tabela 2), o que, de acordo com GRAUER \& LANE (1997), demonstra uma capacidade adequada de conservação renal deste íon. Achados semelhantes foram encontrados por DÓREA et al. (1997) e por MONTEIRO et al. (1993). Desta forma, descarta-se que a perda da capacidade de concentração urinária seja devida à hipotonicidade medular renal por perda de sódio, podendo-se supor que a anfotericina B tenha induzido uma resposta inadequada ao hormônio antidiurético (ADH), caracterizando Diabetes insipidus nefrogênico (DiBARTOLA, 2000).

No período controle, verificou-se traços (em $80 \%$ dos animais) a $1+$ de proteínas na urina, achado normal em cães com densidade urinária acima de 1.025 (DiBARTOLA, 2000). Entretanto, as concentrações 
Tabela 1 - Médias, desvios-padrão (DP), medianas, valores mínimos e máximos da densidade urinária $(\mathrm{M}=$ urina da manhã; $\mathrm{T}=$ urina da tarde) em dez cães tratados com doses terapêuticas de anfotericina $\mathrm{B}$ observados ao longo de dez dias consecutivos e probabilidade calculada pela análise da variância para medidas repetidas.

\begin{tabular}{|c|c|c|c|c|c|}
\hline Período & Média & DP & Mediana & Mínimo & Máximo \\
\hline Manhã & & & & & $\mathrm{P}<0,001$ \\
\hline Controle & 1.035 & 4 & 1.034 & 1.030 & 1.040 \\
\hline M1 & 1.038 & 5 & 1.040 & 1.028 & 1.040 \\
\hline M2 & 1.012 & 4 & 1.012 & 1.006 & 1.016 \\
\hline M3 & 1.014 & 3 & 1.012 & 1.010 & 1.022 \\
\hline M4 & 1.013 & 5 & 1.012 & 1.006 & 1.024 \\
\hline M5 & 1.015 & 3 & 1.015 & 1.010 & 1.022 \\
\hline M6 & 1.014 & 4 & 1.014 & 1.010 & 1.022 \\
\hline M7 & 1.013 & 4 & 1.014 & 1.006 & 1.016 \\
\hline M8 & 1.013 & 2 & 1.012 & 1.010 & 1.016 \\
\hline M9 & 1.015 & 3 & 1.014 & 1.012 & 1.020 \\
\hline M10 & 1.013 & 4 & 1.014 & 1.006 & 1.018 \\
\hline Tarde & & & & & $P<0,001$ \\
\hline Controle & 1.035 & 4 & 1.034 & 1.030 & 1.040 \\
\hline $\mathrm{T} 1$ & 1.013 & 4 & 1.014 & 1.006 & 1.016 \\
\hline $\mathrm{T} 2$ & 1.009 & 3 & 1.008 & 1.004 & 1.016 \\
\hline $\mathrm{T} 3$ & 1.013 & 5 & 1.014 & 1.004 & 1.018 \\
\hline $\mathrm{T} 4$ & 1.014 & 5 & 1.014 & 1.010 & 1.024 \\
\hline T5 & 1.011 & 2 & 1.010 & 1.010 & 1.016 \\
\hline T6 & 1.015 & 3 & 1.014 & 1.012 & 1.022 \\
\hline $\mathrm{T} 7$ & 1.011 & 3 & 1.012 & 1.008 & 1.014 \\
\hline $\mathrm{T} 8$ & 1.012 & 3 & 1.012 & 1.006 & 1.016 \\
\hline T9 & 1.013 & 3 & 1.012 & 1.008 & 1.020 \\
\hline T10 & 1.012 & 3 & 1.012 & 1.008 & 1.018 \\
\hline
\end{tabular}

semelhantes observadas durante o tratamento em urinas com densidade abaixo do normal (Figura 1) representam perda protéica clinicamente significativa (MEYER \& HARVEY, 1998; STRASINGER, 2000) e possivelmente indicam lesão renal provocada pela anfotericina B. CARLSON \& CONDON (1994) também observaram proteinúria variável relacionada ao uso desse fármaco.

Verificou-se a presença de glicose, desde traços, no T1, evoluindo de 3+ até o M8 (Figura 1). Estes achados demonstram que a anfotericina B tem a capacidade de lesar os túbulos proximais, discordando de RUBIN (1988), que não observou alterações neste segmento. A anfotericina B altera a permeabilidade das membranas celulares por meio da formação de poros que permitem o influxo e efluxo de íons e outros solutos (HARVEY \& CHAMPE, 1998), o que acabaria por alterar a absorção da glicose devido a uma permeabilidade ao sódio alterada, sódio este necessário para o
Tabela 2 - Médias, desvios-padrão, medianas, valores mínimos e máximos da excreção fracionada de sódio e potássio ( $\mathrm{T}=$ urina da tarde) em dez cães tratados com doses terapêuticas de anfotericina $\mathrm{B}$, observados ao longo de dez dias consecutivos e respectiva análise da variância para medidas repetidas.

\begin{tabular}{|c|c|c|c|c|c|}
\hline Período & Média & DP & Mediana & Mínimo & Máximo \\
\hline \multicolumn{5}{|c|}{ Sódio (Na\%) } & $\mathrm{p}=0,05$ \\
\hline Controle & 0,39 & 0,26 & 0,37 & 0,08 & 0,71 \\
\hline $\mathrm{T} 1$ & 0,69 & 0,73 & 0,43 & 0,09 & 2,63 \\
\hline $\mathrm{T} 2$ & 0,34 & 0,19 & 0,30 & 0,08 & 0,68 \\
\hline $\mathrm{T} 3$ & 0,66 & 0,52 & 0,69 & 0,05 & 1,50 \\
\hline $\mathrm{T} 4$ & 0,41 & 0,23 & 0,44 & 0,13 & 0,79 \\
\hline T5 & 0,71 & 0,38 & 0,72 & 0,23 & 1,27 \\
\hline T6 & 0,57 & 0,35 & 0,43 & 0,19 & 1,21 \\
\hline $\mathrm{T} 7$ & 0,71 & 0,43 & 0,67 & 0,21 & 1,36 \\
\hline T8 & 0,88 & 0,82 & 0,52 & 0,20 & 2,66 \\
\hline T9 & 0,88 & 0,55 & 0,76 & 0,19 & 1,74 \\
\hline $\mathrm{T} 10$ & 0,79 & 0,58 & 0,52 & 0,18 & 1,93 \\
\hline \multicolumn{5}{|c|}{ Potássio (K\%) } & $\mathrm{p}=0,0003$ \\
\hline Controle & 14,20 & 5,92 & 15,07 & 3,99 & 20,03 \\
\hline $\mathrm{T} 1$ & 18,95 & 9,34 & 20,18 & 2,16 & 31,89 \\
\hline $\mathrm{T} 2$ & 13,61 & 9,07 & 10,99 & 4,25 & 31,69 \\
\hline $\mathrm{T} 3$ & 24,87 & 14,00 & 23,66 & 3,32 & 55,76 \\
\hline $\mathrm{T} 4$ & 22,11 & 8,60 & 21,64 & 8,74 & 35,07 \\
\hline T5 & 29,05 & 8,64 & 27,60 & 16,78 & 43,11 \\
\hline T6 & 21,57 & 8,43 & 23,47 & 6,94 & 33,70 \\
\hline $\mathrm{T} 7$ & 26,01 & 12,79 & 26,02 & 3,89 & 44,86 \\
\hline T8 & 31,42 & 12,70 & 27,21 & 19,34 & 53,40 \\
\hline Т9 & 34,26 & 13,44 & 34,33 & 10,73 & 58,47 \\
\hline T10 & 26,50 & 8,20 & 25,88 & 9,31 & 35,69 \\
\hline
\end{tabular}

funcionamento adequado do co-transporte de glicose (JOLY et al., 1989). A glicosúria também pode ser atribuída à presença de lesão tubular aguda (TILLEY $\&$ SMITH, 2003), uma vez que se observou a presença concomitante do aumento da atividade da GGT urinária (em dois cães) e cilindros granulosos.

Os valores de pH durante o controle oscilaram na faixa de 5,5 a 7,0. Embora estatisticamente significativa apenas na urina da tarde (Tabela 3 ), houve aumento do pH urinário na urina da tarde e na da manhã, tendo sido observado $\mathrm{pH}$ de até 8,5 , o que descarta efeito da onda alcalina pós-prandial. Achados semelhantes foram descritos por JOLY et al. (1989), que citaram aumento do $\mathrm{pH}$ urinário em coelhos. SAWAYA et al. (1995) descreveram a ocorrência de alteração na capacidade de acidificação urinária em seres humanos tratados com este fármaco.

Detectou-se a presença de cilindros granulosos a partir do segundo dia de experimento. Ao 


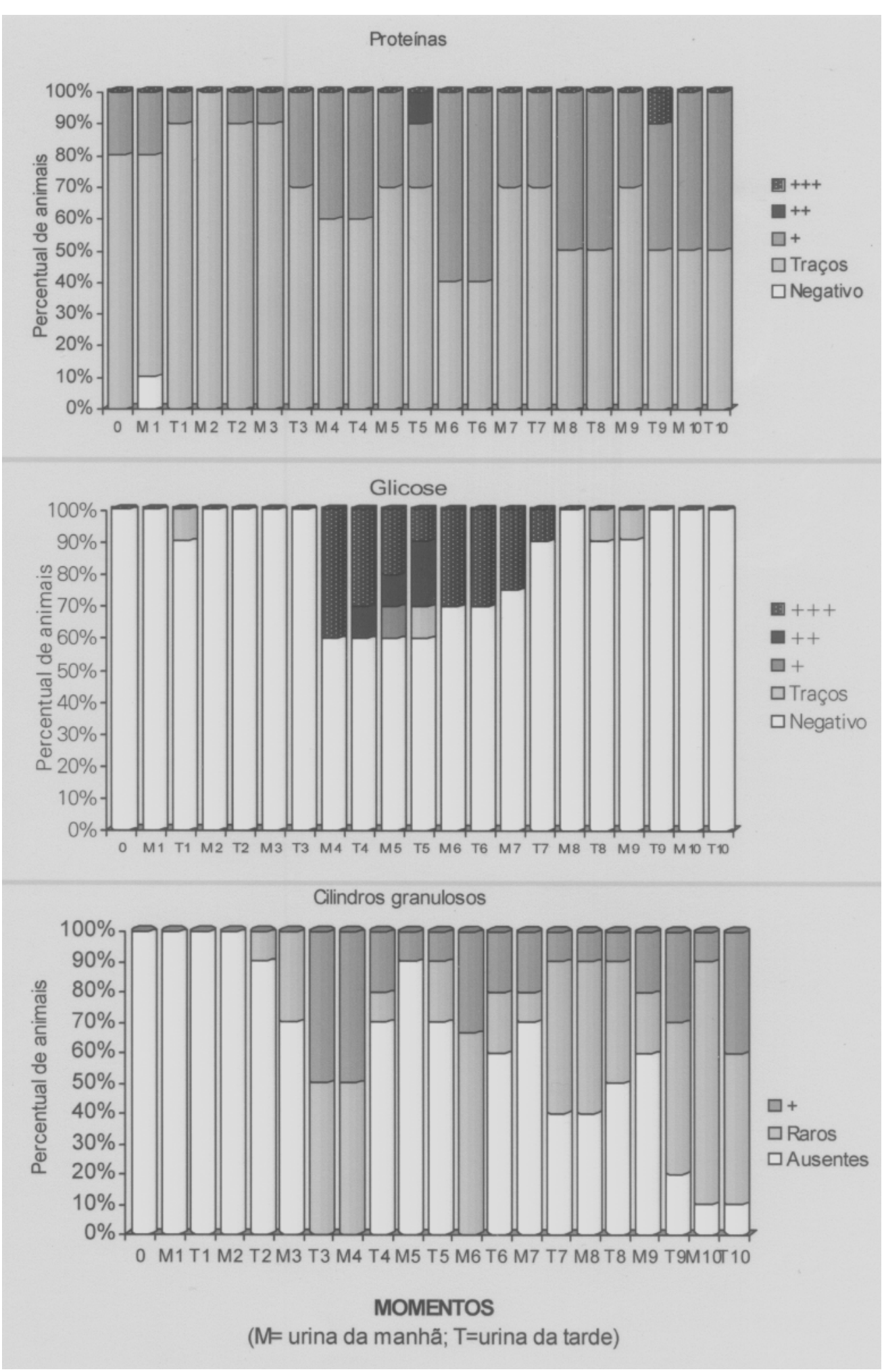

Figura 1 - Freqüência observada de alterações na urinálise de dez cães tratados com doses terapêuticas de anfotericina $\mathrm{B}(0=$ período controle; $M=$ urina da manhã; $\mathrm{T}=$ urina da tarde), monitorados por dez dias consecutivos durante o tratamento. 
Tabela 3 - Médias, desvios-padrão, medianas, valores mínimos e máximos do pH urinário observado em dez cães tratados com anfotericina B ao longo de dez momentos $(\mathrm{M} 0=$ controle) e respectiva análise da variância para medidas repetidas.

\begin{tabular}{|c|c|c|c|c|c|}
\hline Período & Média & $\mathrm{DP}$ & Mediana & Mínimo & Máximo \\
\hline Manhã & & & & & $\mathrm{P}=0,179$ \\
\hline M0 & 6,35 & 0,53 & 6,50 & 5,50 & 7,00 \\
\hline M1 & 6,85 & 0,47 & 7,00 & 6,00 & 7,50 \\
\hline M2 & 7,00 & 0,53 & 7,00 & 6,50 & 8,00 \\
\hline M3 & 7,10 & 0,61 & 7,25 & 6,00 & 8,00 \\
\hline M4 & 7,10 & 0,61 & 7,25 & 6,00 & 8,00 \\
\hline M5 & 7,30 & 1,11 & 7,75 & 5,50 & 8,50 \\
\hline M6 & 7,10 & 0,94 & 7,50 & 5,50 & 8,50 \\
\hline M7 & 7,30 & 0,48 & 7,25 & 6,50 & 8,00 \\
\hline M8 & 7,10 & 0,88 & 7,25 & 6,00 & 8,50 \\
\hline M9 & 7,00 & 0,91 & 7,00 & 5,50 & 8,50 \\
\hline M10 & 7,30 & 0,42 & 7,50 & 6,50 & 8,00 \\
\hline Tarde & & & & & $P=0,0014$ \\
\hline T0 & 6,30 & 0,54 & 6,50 & 5,50 & 7,00 \\
\hline $\mathrm{T} 1$ & 7,10 & 1,10 & 7,25 & 5,50 & 8,50 \\
\hline $\mathrm{T} 2$ & 6,85 & 0,47 & 7,00 & 6,00 & 7,50 \\
\hline $\mathrm{T} 3$ & 7,55 & 0,86 & 7,50 & 6,00 & 8,50 \\
\hline $\mathrm{T} 4$ & 7,00 & 0,94 & 7,25 & 5,50 & 8,50 \\
\hline T5 & 7,25 & 0,75 & 7,00 & 6,00 & 8,50 \\
\hline T6 & 7,25 & 0,86 & 7,50 & 5,50 & 8,50 \\
\hline $\mathrm{T} 7$ & 7,75 & 0,63 & 7,75 & 7,00 & 8,50 \\
\hline $\mathrm{T} 8$ & 7,45 & 0,50 & 7,50 & 7,00 & 8,50 \\
\hline $\mathrm{T} 9$ & 7,35 & 0,41 & 7,50 & 6,50 & 8,00 \\
\hline $\mathrm{T} 10$ & 7,45 & 0,55 & 7,50 & 6,50 & 8,50 \\
\hline
\end{tabular}

término do período, $90 \%$ dos animais apresentavam cilindrúria. Os cilindros granulosos formam-se no interior dos túbulos renais em conseqüência de lesão tubular (MEYER \& HARVEY, 1998). Apesar de estarem presentes em quantidade baixa (até um cilindro por campo), deve-se salientar que o $\mathrm{pH}$ urinário, em praticamente todos os momentos, apresentava-se dentro da faixa de 7,0 a 8,5 e a densidade urinária estava abaixo de 1.025. Uma vez que se desintegram rapidamente em urinas diluídas e/ou alcalinas (TILLEY \& SMITH, 2003), o número de cilindros formados deveria ser bem maior, representando um maior acometimento do parênquima renal.

Foi observado aumento significativo das médias da EFK ao longo do tratamento (Tabela 3). Atribui-se à anfotericina $\mathrm{B}$ a capacidade de provocar perda de íons potássio através da urina, como descrito por DÓREA et al. (1997), que demonstraram aumento da EFK em ratos. A perda de íons potássio é atribuída à alteração na permeabilidade das membranas das células dos túbulos distais renais, causada pela formação de canais ionóforos, possibilitando a saída passiva do potássio, por meio de gradiente eletroquímico favorável (SAWAYA et al., 1995). Não se pode descartar que a poliúria provocada pela anfotericina B atue como fator agravante da perda de potássio (DiBARTOLA, 2000), já que foi observado aumento do volume urinário, embora não tenham sido utilizadas gaiolas metabólicas para permitir uma quantificação objetiva.

Houve um aumento significativo e progressivo das médias séricas de uréia e creatinina (Tabela 4), achado corroborado por SABRA et al. (1990), os quais afirmaram que a anfotericina B tem a capacidade de provocar diminuição do ritmo de filtração glomerular. HARVEY \& CHAMPE (1998) descreveram aumento da uréia sangüínea provocado pela anfotericina B.

BAGATIN \& CUCÉ (1983) postularam que a nefrotoxicidade produzida pela anfotericina B era exclusivamente dose-dependente; porém, os resultados encontrados sugerem que há também uma susceptibilidade individual, já apontada por RANDALL et al. (1996), uma vez que se observou azotemia em três cães, após duas aplicações do medicamento.

Ocorreu um aumento significativo das médias da atividade da GGT urinária dentro do intervalo de normalidade; entretanto, com alta variação entre os indivíduos. Em alguns casos, a GGT alcançou valor muito acima do normal para, no momento seguinte, voltar à normalidade, seguido por novo aumento, sem resolução da lesão renal, já que se detectou glicosúria e cilindrúria. Estes achados discordam de RIVERS et al. (1996), que apontaram a GGT urinária como um sensível marcador da presença e também da persistência de lesão renal.

\section{CONCLUSÕES}

Os defeitos de acidificação urinária, de perda de potássio e da incapacidade de concentração urinária encontrados neste trabalho corroboram o conceito de que a anfotericina B causa danos diretos aos túbulos renais distais, enquanto a glicosúria comprova lesões nos túbulos proximais. A anfotericina $\mathrm{B}$ induz acidose tubular renal do tipo I e Diabetes insipidus nefrogênico em cães. A perda na capacidade de concentração urinária é a primeira alteração detectada. A GGT urinária não tem eficiência como método precoce de diagnóstico de lesão renal induzida por anfotericina B. Avaliação da função renal por dosagens séricas de uréia, creatinina e potássio é indicada antes de cada aplicação do fármaco.

Ciência Rural, v.36, n.6, nov-dez, 2006. 
Tabela 4 - Médias, desvios-padrão, medianas, valores mínimos e máximos de uréia sérica, creatinina sérica e $\gamma$ glutamiltransferase (GGT) urinária $(\mathrm{T}=$ amostra da tarde) em dez cães tratados com doses terapêuticas de anfotericina B, observados ao longo de dez dias consecutivos e probabilidade calculada pela análise da variância para medidas repetidas.

\begin{tabular}{|c|c|c|c|c|c|}
\hline Período & Média & DP & Mediana & Mínimo & Máximo \\
\hline \multicolumn{5}{|c|}{ Uréia (mg/dl) } & $P=0,0011$ \\
\hline Controle & 42,33 & 9,80 & 43,00 & 26,00 & 55,90 \\
\hline $\mathrm{T} 1$ & 43,38 & 11,27 & 39,50 & 30,00 & 58,90 \\
\hline $\mathrm{T} 2$ & 47,82 & 12,06 & 46,15 & 32,79 & 71,00 \\
\hline $\mathrm{T} 3$ & 52,32 & 12,31 & 56,50 & 30,00 & 66,70 \\
\hline $\mathrm{T} 4$ & 53,62 & 16,25 & 60,00 & 27,00 & 72,40 \\
\hline T5 & 55,49 & 11,59 & 61,35 & 35,00 & 65,00 \\
\hline T6 & 60,56 & 13,51 & 61,09 & 44,00 & 85,50 \\
\hline $\mathrm{T} 7$ & 63,69 & 13,93 & 62,00 & 38,00 & 88,80 \\
\hline $\mathrm{T} 8$ & 63,22 & 11,42 & 60,33 & 53,00 & 91,00 \\
\hline T9 & 67,14 & 13,26 & 64,75 & 52,36 & 97,00 \\
\hline $\mathrm{T} 10$ & 73,40 & 16,83 & 65,50 & 61,00 & 111,10 \\
\hline \multicolumn{5}{|c|}{ Creatinina (mg/dl) } & $\mathrm{P}(\log )<0,0001$ \\
\hline Controle & 0,99 & 0,19 & 1,00 & 0,70 & 1,20 \\
\hline $\mathrm{T} 1$ & 1,00 & 0,18 & 1,00 & 0,80 & 1,30 \\
\hline $\mathrm{T} 2$ & 1,05 & 0,18 & 1,05 & 0,80 & 1,30 \\
\hline $\mathrm{T} 3$ & 1,34 & 0,52 & 1,20 & 0,80 & 2,70 \\
\hline $\mathrm{T} 4$ & 1,43 & 0,82 & 1,20 & 0,90 & 3,70 \\
\hline $\mathrm{T} 5$ & 1,50 & 1,03 & 1,25 & 0,90 & 4,40 \\
\hline T6 & 1,51 & 0,97 & 1,25 & 0,90 & 4,20 \\
\hline $\mathrm{T} 7$ & 1,70 & 1,15 & 1,30 & 0,90 & 4,90 \\
\hline $\mathrm{T} 8$ & 1,84 & 1,23 & 1,40 & 1,30 & 5,30 \\
\hline $\mathrm{T} 9$ & 1,97 & 1,34 & 1,50 & 1,30 & 5,70 \\
\hline $\mathrm{T} 10$ & 2,12 & 1,47 & 1,60 & 1,30 & 6,20 \\
\hline \multicolumn{5}{|c|}{ GGT Urinária (U/L) } & $\mathrm{P}(\log )=0,0042$ \\
\hline Controle & 18,54 & 10,86 & 15,65 & 9,00 & 39,00 \\
\hline $\mathrm{T} 1$ & 21,72 & 17,43 & 14,55 & 7,00 & 62,50 \\
\hline $\mathrm{T} 2$ & 40,80 & 25,62 & 31,05 & 10,00 & 90,00 \\
\hline $\mathrm{T} 3$ & 34,81 & 25,07 & 23,20 & 16,10 & 85,00 \\
\hline $\mathrm{T} 4$ & 43,23 & 27,07 & 39,85 & 12,50 & 77,00 \\
\hline $\mathrm{T} 5$ & 41,12 & 27,83 & 36,60 & 12,50 & 95,00 \\
\hline $\mathrm{T} 6$ & 42,84 & 23,74 & 34,50 & 12,50 & 90,00 \\
\hline $\mathrm{T} 7$ & 36,85 & 25,16 & 27,85 & 13,50 & 88,90 \\
\hline $\mathrm{T} 8$ & 55,38 & 50,83 & 38,95 & 15,00 & 189,00 \\
\hline $\mathrm{T} 9$ & 44,32 & 28,09 & 33,55 & 14,20 & 93,70 \\
\hline $\mathrm{T} 10$ & 51,57 & 27,88 & 40,80 & 20,00 & 95,00 \\
\hline
\end{tabular}

\section{APRESENTAÇÃO}

Este trabalho é parte da dissertação de mestrado do primeiro autor, apresentada ao Curso de Pós-graduação em Medicina Veterinária da Faculdade de Medicina Veterinária e Zootecnia da Universidade Estadual Paulista "Júlio de Mesquita Filho” (FMVZ-UNESP), campus Botucatu, SP.

\section{FONTES DE AQUISIÇÃO}

${ }^{a}$ Fungizon ${ }^{\circledR} 50 \mathrm{mg}$ - Bristol-Myers Squibb.

${ }^{\text {b }}$ Combur Test ${ }^{\circledR}-$ Roche.

${ }^{\mathrm{c}}$ Gama $\mathrm{GT}^{\circledR}$ - Celm.

${ }^{\mathrm{d}}$ Creatinina slides vitro products chemistry ortho-clinical diagnostics ${ }^{\circledR}-$ Johnson \& Johnson.

${ }^{\mathrm{e}} \mathrm{Na}+$ slides vitro products chemistry ortho-clinical diagnostics ${ }^{\circledR}$ - Johnson \& Johnson.

${ }^{\mathrm{f}} \mathrm{K}+$ slides vitro products chemistry ortho-clinical diagnostics ${ }^{\circledR}$ - Johnson \& Johnson.

g Vitro System Chemistry ${ }^{\circledR}$ 750XRc - Johnson \& Johnson.

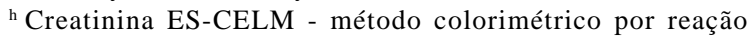
cinética com picrato alcalino - Celm.

${ }^{\mathrm{i}}$ Uréia ES-CELM - método enzimático colorimétrico - Celm. ${ }^{\mathrm{j}}$ Liquemine ${ }^{\circledR}-$ Roche.

\section{REFERÊNCIAS}

BAGATIN, E.; CUCÉ, L.C. Nefrotoxicidade da anfotericina B em relação à dose total administrada. Anais Bras Dermatol, v.58, n.6, p.261-264, 1983.

CARLSON, M.A.; CONDON, R.E. Nephrotoxicity of amphotericin B. J Am Coll Surg, v.179, p.361-381, 1994.

DeSCHEPPER, J. et al. Urinary (-glutamiltransferase and degree of renal dysfunction in 75 bitches with pyometra. Res Vet Sci, v.46, p.396-400, 1989.

DiBARTOLA, S.P. Clinical approach and laboratory evaluation of renal disease. In: ETTINGER, S.J.; FELDMAN, E.C. (Eds). Textbook of veterinary internal medicine. 5.ed. Philadelphia: Saunders, 2000. p.1600-1614.

DÓREA, E.L. et al. Nephrotoxicity of amphotericin B is attenuated by solubilizing with lipid emulsion. J Am Soc Nephrol, v.8, p.1415-1422, 1997.

GRAUER, G.F.; LANE, I.F. Insuficiência renal aguda. In: ETTINGER, S.J.; FELDMAN, E.C. (Eds). Tratado de medicina interna veterinária. 4.ed. São Paulo: Manole, 1997. p.2374-2393.

HARVEY, R.A.; CHAMPE, P.C. Fármacos antifúngicos. In: HARVEY, R.A. Farmacologia ilustrada. Porto Alegre: Artmed, 1998. p.337-345.

JOLY, V. et al. Incorporation of amphotericin B (amb) into lipossomes alters amb-induced acute nephrotoxicity. J Pharmacol Exp Ther, v.251, n.1, p.311-316, 1989.

MEYER, J.D.; HARVEY, W.J. Assessment of renal function, urinalysis, and water balance. In: Veterinary laboratory medicine interpretation and diagnosis. 2.ed. Philadelphia: Saunders, 1998. Chap.10, p.221-235.

MONTEIRO, J.M. et al. Nefrotoxicidade aguda da anfotericina no cão. Rev Hosp Clin Fac Med S Paulo, v.48, n.2, p.5459,1993

RANDALL, S.R. et al. Nephrotoxicity of amphotericin B administered to dogs in a fat emulsion five percent dextrose solution. Am J Vet Res, v.57, n.7, p.1054-1058, 1996.

Ciência Rural, v.36, n.6, nov-dez, 2006. 
RIVERS, B.J. et al. Evaluation of urine gamma-glutamyl transpeptidade-to-creatinine ratio as a diagnostic tool in an experimental model of aminoglycoside-induced acute renal failure in the dog. J Am Anim Hosp Assoc, v.32, p.323-336, 1996.

RUBIN, S.I. Nefrotoxicidade da anfotericina B. In: KIRK, R.W. Atualização terapêutica veterinária pequenos animais IX. 9.ed. São Paulo: Manole, 1988. p.1442-1447.

SABRA, R. et al. Mechanisms of amphotericin B-induced reduction of the glomerular filtration rate: a micropuncture study. J Pharmacol Exp Ther, v.253, n.1, p.34-37, 1990.
SAWAYA, B.P. et al. Amphotericin B nephrotoxicity: the adverse consequences of altered membrane properties. J Am Nephrol, v.6., n.2, p.154-164, 1995.

SCOTT, D.W. et al. Fungal skin diseases. In: MILLER, W.H. Small animal dermatology. Philadelphia: Saunders, 2001. p.337-422.

STRASINGER, S.K. Uroanálise \& fluidos biológicos. São Paulo: Premier, 2000. 233p.

TILLEY, L.P.; SMITH, F.W.K. Jr. Consulta veterinária em cinco minutos espécies canina e felina. 2.ed. São Paulo: Manole, 2003. 1423p. 